\title{
The Characterization and Study of Physical Parameters of Ge Modified Se-Sn-Pb Chalcogenide System
}

\author{
Prashant Kumar $^{1,2^{*}}$, Vivek Modgil ${ }^{2}$, V. S. Rangra ${ }^{2}$ \\ ${ }^{1}$ Government Senior Secondary Boys School Lalpani, Shimla, India; ${ }^{2}$ Department of Physics, H. P. University, Summer Hill, Shimla, \\ India. \\ Email: "prashantshrm5@gmail.com, vivekmodgilphysicshpu@gmail.com
}

Received March $14^{\text {th }}, 2013$; revised April 14 ${ }^{\text {th }}, 2013$; accepted April 21 $1^{\text {st }}, 2013$

Copyright (C) 2013 Prashant Kumar et al. This is an open access article distributed under the Creative Commons Attribution License, which permits unrestricted use, distribution, and reproduction in any medium, provided the original work is properly cited.

\begin{abstract}
In the present paper, we have studied the effect of Ge addition on the physical properties of $\mathrm{Se}-\mathrm{Sn}-\mathrm{Pb}$ chalcogenide material. The necessary physical parameters which have important role in determining the structure and strength of the material viz. constraints, coordination number etc. have been calculated. The increasing trend has been found in cohesive energy, heat of atomization and mean bond energy. The glass transition has been studied using the Tichy-Ticha and Lankhorst approaches, which also increases with the increasing Ge contents. The increase in these physical parameters is due to the increasing covalent character in the material.
\end{abstract}

Keywords: Quaternary Chalcogenide Glasses; Heat of Atomisation; Mean Bond Energy; Glass Transition Temperature; SEM

\section{Introduction}

Material science investigates the relationship between the structures of material at atomic or molecular scales and their macroscopic properties. Nowadays, in the field of chalcogenide glasses a lot of attention has been devoted to the characterization and improvement of the properties of chalcogenide glasses, especially for those materials which are used in the switching memories. The glass transition temperature and the related nature of the chemical bond are important parameters for characterization of chalcogenide glasses. These materials can be reversibly switched between the amorphous and crystalline state and find applications in rewritable optical recording and in electrically programmable non-volatile memories [1-3].

Chalcogenide glasses possess properties intermediate between organic polymers and oxide glasses. These glasses are less robust, more weakly bonded materials than oxides [4].The amorphous semiconductor like chalcogenide glasses are basically insensitive to doping and behave as p-type semiconductor because of pinning of Fermi level near the middle of band gap. A long standing and important problem in $\mathrm{Se}-\mathrm{Ge}-\mathrm{Pb}$ based chalcogenide glasses has been Carrier Type Reversal (CTR). However,

${ }^{*}$ Corresponding author. it has been realized by Mott that charged additives could change the ratio of valence-alternation pairs to such an extent that the Fermi energy could become unpinned, which causes carrier type reversal in certain chalcogenide systems. Metallic additives such as $\mathrm{Bi}$ and $\mathrm{Pb}$ in chalcogenide glasses enter the network as charged species, altering the concentration of valence-alternation pairs, which is located closely above the loan pair band of selenium. This feature makes $\mathrm{Pb}$ unique in the contest to $\mathrm{p}$ to $\mathrm{n}$ transition of chalcogenide glasses [5-9].

\section{Experimental Details}

Bulk samples of $\mathrm{Se}_{74} \mathrm{Sn}_{8} \mathrm{~Pb}_{18-x} \mathrm{Ge}_{x}(x=3,7,8,9,10,11)$ have been prepared by conventional melt quenching technique. High purity (99.999\%) elements $\mathrm{Ge}, \mathrm{Se}, \mathrm{Sn}$ and $\mathrm{Pb}$ in the appropriate weight proportion are weighed and vacuum sealed $\left(10^{-6} \mathrm{~Pa}\right)$ in quartz ampoules and heated up to $980^{\circ} \mathrm{C}$ in a rocking furnace at a heating rate of $3^{\circ} \mathrm{C}-4^{\circ} \mathrm{C} / \mathrm{min}$. The ampoules are frequently rocked at the highest temperature for $8 \mathrm{hrs}$. The quenching is done in ice-cold water immediately after taking out the ampoules from the furnace. The ampoules are then dipped in $\mathrm{HF}+\mathrm{H}_{2} \mathrm{O}_{2}$ solution in order to remove the sticky material from the quartz tube.

The bulk material is finally grinded to powder, then 
the diffraction patterns of the material are taken with Philips Xpert-Pro diffractometer PW3050/60 having step size 0.034 using $\mathrm{Cu}-\mathrm{K} \alpha$ radiation $(\lambda=1.54837 \AA)$ as shown in Figure 1. The absence of any sharp peaks in Xray difractrograms shows the amorphous nature of material $\mathrm{Se}_{74} \mathrm{Sn}_{8} \mathrm{~Pb}_{18-x} \mathrm{Ge}_{x}(x=7,8,9,10,11$ at \%). But at $x=$ 3 the sample becomes crystalline as shown in inset of XRD difractrograms in Figure 1.

Scanning electron microscope is the technique which is used to know the surface morphology and structure of the material. We are observing some structural inhomogenieties in material which are due to partial nano phase separation, as is clear in the SEM micrographs as shown in Figure 2. The phase separation in the material is also confirmed from the presence of halos in the X-ray diffractograms.

\section{Theoretical Study and Discussion}

The various parameters viz. coordination number, fraction of floppy modes, loan pairs, heat of atomization, bond energy, cohesive energy and glass transition temperature are calculated for our Se-Sn-Ge-Pb quaternary chalcogenide glassy system.

\subsection{Coordination Number and Constraints}

Phillips, Thorpe and Tanaka have introduced in the constraint theories that there exist two topological thresholds 2.4 and 2.67 known as mechanical and chemical thresholds. The Chalcogenide glasses with coordination number $\langle r\rangle$ less than 2.4 are under constrained or loosely connected (polymeric glasses) and glasses with $\langle r\rangle$ greater than 2.4 are over constrained or rigidly connected (amorphous solids) [10]. The chemical threshold at $\langle r\rangle=2.67$ corresponds to a structural transition from a two-dimensional to a three-dimensional network. It has also been predicted that there exists a critical composition corresponding to an average coordination number $\langle r\rangle=2.4$,

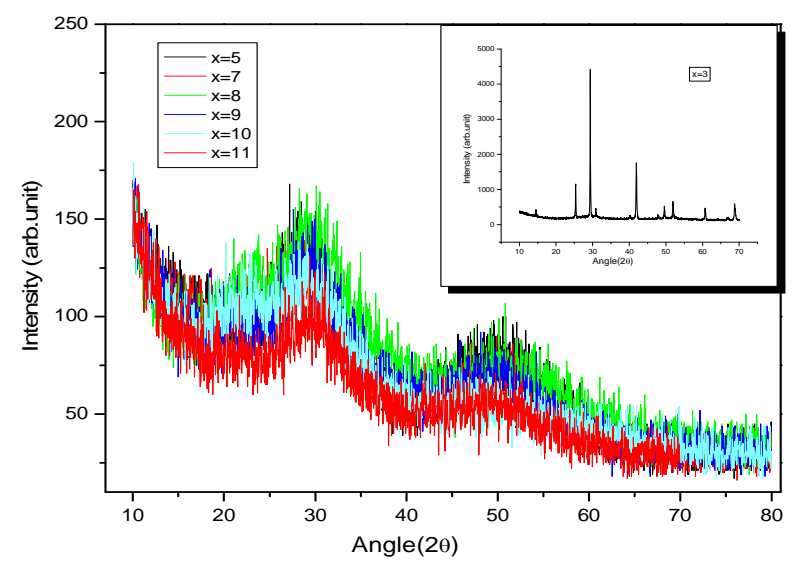

Figure 1. X-Ray Diffactograms of the chalcogenide compositions $\mathrm{Se}_{74} \mathrm{Sn}_{8} \mathrm{~Pb}_{18-x} \mathrm{Ge}_{x}(3 \leq x \leq 11)$. at which the number of constraints are balanced by the number of degrees of freedom $\left(N_{d}\right)$ available in the network i.e. $\left(N_{c o}=N_{d}\right)$. At this stage the tendency of glass formation is maximum and is known as rigidity percolation threshold. For mechanical constraints there exist two constraints $N_{\alpha}=r / 2$ is known as bond stretching constraints per atom and $N_{\beta}=2 r-3$ is known as bond bending constraints per atom on the network.

The total number of constraints are given by $N_{c o}=N_{\alpha}$ $+N_{\beta}$. In our quarternary system the value of $\langle r\rangle$ varies from 2.30 to 2.38 and approaches mechanical threshold. The total number of constraints $\left(N_{c o}\right)$ plays an important role in structural determination. The average coordination number $\langle r\rangle$ has been calculated using the relation

$$
\langle r\rangle=\frac{\alpha N_{\mathrm{Se}}+\beta N_{\mathrm{Ge}}+\gamma N_{\mathrm{Pb}}+\delta N_{\mathrm{Sn}}}{100}
$$

where $\alpha, \beta, \gamma$ and $\delta$ are the at $\%$ of $\mathrm{Se}, \mathrm{Ge}, \mathrm{Pb}$ and $\mathrm{Sn}$ respectively and $N_{\mathrm{Ge}}=4, N_{\mathrm{Se}}=2, N_{\mathrm{Pb}}=2$ and $N_{\mathrm{Sn}}=4$ are coordination numbers. M. F. Thorpe [11] has pointed out that under coordinated networks would possess a finite fraction of zero frequency normal vibrational modes, floppy modes. The fraction, $f$ of zero frequency modes is given as

$$
f=2-\frac{5}{6}\langle r\rangle
$$

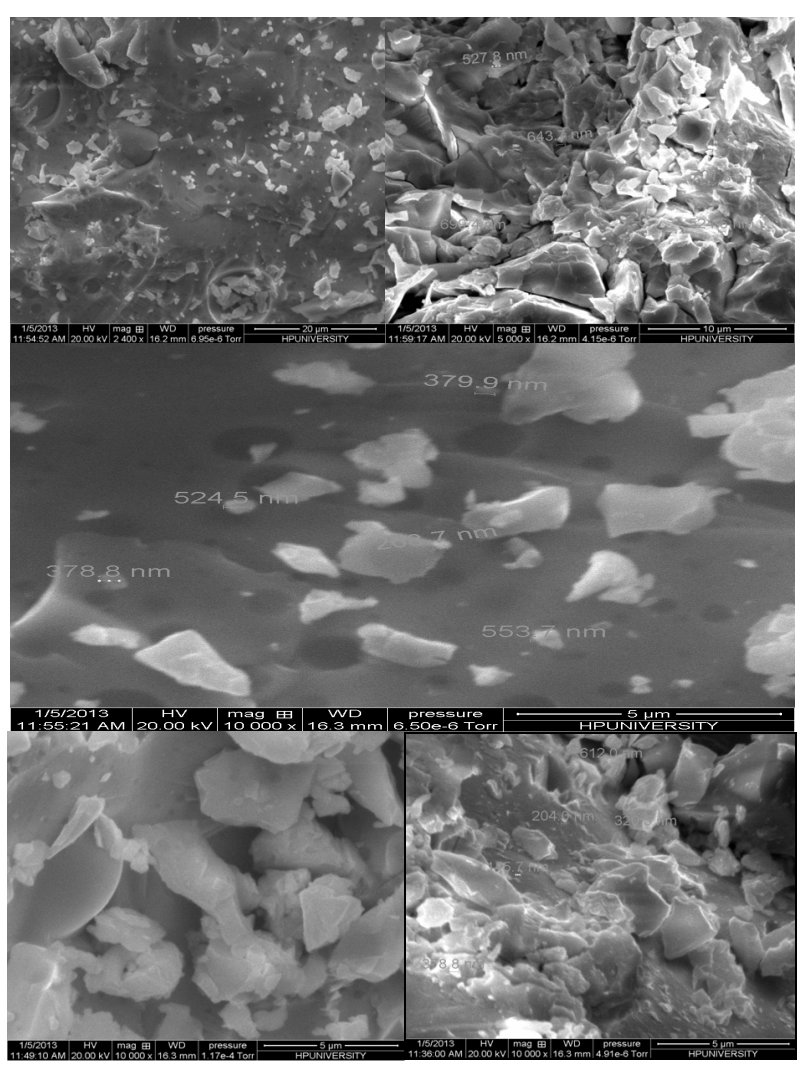

Figure 2. SEM micrographs of the chalcogenide glass $\mathrm{Se}_{74} \mathrm{Sn}_{8} \mathrm{~Pb}_{18-x} \mathrm{Ge}_{x}(x=7,8,9,10,11)$. 
Here $\langle r\rangle$ is the average coordination number. In our system the number of floppy modes are approaching zero with the addition of Ge. So system is passing from floppy network to rigid network [12-14]. The average coordination number $\langle r\rangle$, bond stretching constraints $\left(N_{\alpha}\right)$, bond bending constraints $\left(N_{\beta}\right)$, average number of constraints $N_{c o}=N_{\alpha}+N_{\beta}$, fraction of floppy modes $(f)$ and loan pair (L) for various compositions with Ge are listed in Table 1.

\subsection{Role of Lone Pair Electrons in the Glass Forming Ability}

The number of lone pairs of a chalcogenide glass system has been calculated by the method proposed by Phillips

$$
L=V-\langle r\rangle
$$

Here $\mathrm{L}$ and $\mathrm{V}$ are lone pair electrons and valence electrons respectively. For the glassy system $\mathrm{Se}_{74} \mathrm{Sn}_{8} \mathrm{~Pb}_{18-x} \mathrm{Ge}_{x}$ $(x=7,8,9,10,11$ at $\%)$ the number of lone pair electrons are obtained by using equation (3) and are listed in Table 1. It is inferred from the Table 1 and Figure 3 that with the increase in content of $\mathrm{Ge}$ the number of lone pair of electrons decreases continuously for the $\mathrm{Se}_{74} \mathrm{Sn}_{8} \mathrm{~Pb}_{18-x} \mathrm{Ge}_{x}$ $(x=7,8,9,10,11)$ glassy system. This result is caused by the interaction between the Ge ion and the lone pair electrons of a bridging Se atom. The interaction decreases the number of lone-pair electrons in the glassy system. According to Zhenhua, lone pair electrons are necessary for obtaining the system in its vitreous state $[15,16]$.

\subsection{Deviation from the Stoichiometry of Composition}

The parameter $R$ which determines the deviation from stoichiometry is expressed by the ratio of covalent bonding possibilities of chalcogen atom to that of non-chalcogen atoms. For the $\mathrm{Se}_{\alpha} \mathrm{Ge}_{\beta} \mathrm{Pb}_{\gamma} \mathrm{Sn}_{\delta}$ system, the quantity $R$ is defined by

Table 1. The average coordination number $\langle r\rangle$, bond bending constraints $N_{\alpha}$, bond bending constraints $N_{\beta}$, average number of constraints $N_{c o}=N_{\alpha}+N_{\beta}$ fraction of floppy modes $(f)$ and loan pair $(L)$ for various compositions.

\begin{tabular}{ccccccc}
\hline Composition & $<r>$ & $N_{\alpha}$ & $N_{\beta}$ & $N_{c o}$ & $f$ & $\mathrm{~L}=V-r$ \\
\hline $\mathrm{Se}_{74} \mathrm{Sn}_{8} \mathrm{~Pb}_{11} \mathrm{Ge}_{7}$ & 2.30 & 1.15 & 1.60 & 2.75 & 0.0833 & 3.18 \\
$\mathrm{Se}_{74} \mathrm{Sn}_{8} \mathrm{~Pb}_{10} \mathrm{Ge}_{8}$ & 2.32 & 1.16 & 1.64 & 2.80 & 0.0667 & 3.16 \\
$\mathrm{Se}_{74} \mathrm{Sn}_{8} \mathrm{~Pb}_{9} \mathrm{Ge}_{9}$ & 2.34 & 1.17 & 1.68 & 2.85 & 0.05 & 3.14 \\
$\mathrm{Se}_{74} \mathrm{Sn}_{8} \mathrm{~Pb}_{8} \mathrm{Ge}_{10}$ & 2.36 & 1.18 & 1.72 & 2.90 & 0.0333 & 3.12 \\
$\mathrm{Se}_{74} \mathrm{Sn}_{8} \mathrm{~Pb}_{7} \mathrm{Ge}_{11}$ & 2.38 & 1.19 & 1.76 & 2.95 & 0.0167 & 3.10 \\
\hline
\end{tabular}

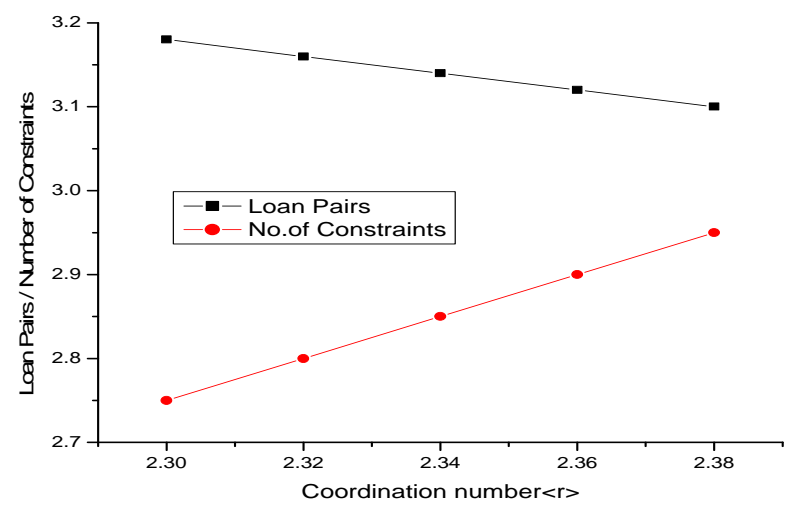

Figure 3. Variation of loan pairs and number of constraints with coordination number of $\mathrm{Se}_{74} \mathrm{Sn}_{8} \mathrm{~Pb}_{18-x} \mathrm{Ge}_{x}(x=7,8,9$, 10, 11) glassy system.

$$
R=\frac{\beta Z \mathrm{Se}}{\alpha Z \mathrm{Ge}+\gamma Z \mathrm{~Pb}+\delta Z \mathrm{Sn}}
$$

where $\alpha, \beta, \gamma$ and $\delta$ are the atomic fractions of $\mathrm{Ge}, \mathrm{Se}, \mathrm{Pb}$, and Sn respectively. The threshold at $R=1$ the point of existence of only heteropolar bonds marks the minimum selenium content For $R>1$, system is chalcogen rich. In our composition $\mathrm{Se}_{74} \mathrm{Sn}_{8} \mathrm{~Pb}_{18-x} \mathrm{Ge}_{x}$ the deviation from the stoichimetry is $R>1$, which shows chalcogen rich system $[17,18]$.

\subsection{Bond Energy and Cohesive Energy}

In chalcogenide system $\mathrm{Se}_{74} \mathrm{Sn}_{8} \mathrm{~Pb}_{18-x} \mathrm{Ge}_{x}(x=7,8,9,10$, 11 ), there is comparatively more probability of bonds formation of the heteropolar bonds as compare to homopolar bonds. The chemically ordered network $(\mathrm{CON})$ [19] model has suggested that heteropolar bonds are preferred over homopolar bonds and they are formed in the order of their decreasing bond energy. The Ge-Se glassy system is a covalent chalcogenide system. From Raman scattering studies, it has been realized that the local structure of Ge-Se glasses consists of chain segments of edge-sharing $\mathrm{GeSe}_{2}$ and corner-sharing $\mathrm{GeSe}_{4}$ tetrahedral structure which produces more attracting sites for impurities atoms when added to the material. These have a pronounced effect on the structure of amorphous material. In selenium based chalcogenide glasses the metallic atoms play a dual role as network modifiers in Se rich side and network formers in Se deficient side and changes the properties considerably [19].

The bond energy of heteropolar bonds can be calculated by the method suggested by Pauling using the bond energy of homopolar bonds and the electronegativity of the atoms involved. The bond energy of heteronuclear bond is given by

$$
D_{(A-B)}=\left[D_{(A-A)} D_{(B-B)}\right]^{1 / 2}+30\left(\chi_{A}-\chi_{B}\right)^{2}
$$

where $D_{(A-B)}=$ bond energy of heteronuclear bond, $D_{(A-A)}$ 
and $D_{(B-B)}$ are the bond energies of homonuclear bonds The bond energies of the bonds are taken as $\mathrm{Se}-\mathrm{Se}=$ $44.00 \mathrm{Kcal} / \mathrm{mol}, \mathrm{Ge}-\mathrm{Ge}=37.60 \mathrm{Kcal} / \mathrm{mol} \mathrm{Sn}-\mathrm{Sn}=34.20$ $\mathrm{Kcal} / \mathrm{mol}, \mathrm{Pb}-\mathrm{Pb}=20.48 \mathrm{Kcal} / \mathrm{mol} \mathrm{Se}-\mathrm{Ge}=49.41$ $\mathrm{Kcal} / \mathrm{mol}, \mathrm{Se}-\mathrm{Sn}=49.23 \mathrm{Kcal} / \mathrm{mol}, \mathrm{Se}-\mathrm{Pb}=31.47$ $\mathrm{Kcal} / \mathrm{mol}$ respectably [12]. $\chi_{A}$ and $\chi_{B}$ are the electronegativity values of $A$ and $B$ respectively. The electronegativities for $\mathrm{Se}, \mathrm{Ge}, \mathrm{Sn}$ and $\mathrm{Pb}$ according to pauling scale are $2.55,2.01,1.96$ and 2.33 respectively [20,21].

The Ge-Se bonds have higher bond energy than $\mathrm{Pb}-\mathrm{Se}$ bonds. In the present $\mathrm{Se}-\mathrm{Sn}-\mathrm{Ge}-\mathrm{Pb}$ system, the substitution of $\mathrm{Ge}$ with $\mathrm{Pb}$ atom results in the increase of $\mathrm{Ge}-\mathrm{Se}$ bonds and a reduction in $\mathrm{Pb}$-Se bonds. The nature of the $\mathrm{Pb}-\mathrm{Se}$ bond is ionocovalent and that of $\mathrm{Ge}-\mathrm{Se}$ bond has covalent character. Thus increasing concentration of GeSe bonds causes the increasing covalent character in the material hence strengthening the network $[22,23]$. So the addition of Ge results in an increase in the cohesive energy of $\mathrm{Se}_{74} \mathrm{Sn}_{8} \mathrm{~Pb}_{18-} \mathrm{Ge}_{x}$ (where $x=7,8,9,10,11$ ) system as shown in Figure 4. The cohesive energies of the compositions are tabulated in Table 2.

\subsection{Average Heat of Atomization}

According to Pauling the heat of atomization $H_{S}(A-B)$ at standard temperature and pressure of a binary semiconductor formed from atoms $A$ and $B$ is the sum of the heat of formation $\triangle H$ and the average of the heats of atomization of $H_{S}^{A}$ and $H_{S}^{B}$ that corresponds to the average non polar bond energy of the two atoms $[18,19]$.

$$
H_{S}(A-B)=\Delta H+\frac{1}{2}\left(H_{S}^{A}+H_{S}^{B}\right)
$$

The first term in the Equation (9) is proportional to the square of the difference between the electronegativities $\chi_{A}$ and $\chi_{B}$ of the two atoms

$$
\Delta H \propto\left(\chi_{A}-\chi_{B}\right)^{2}
$$

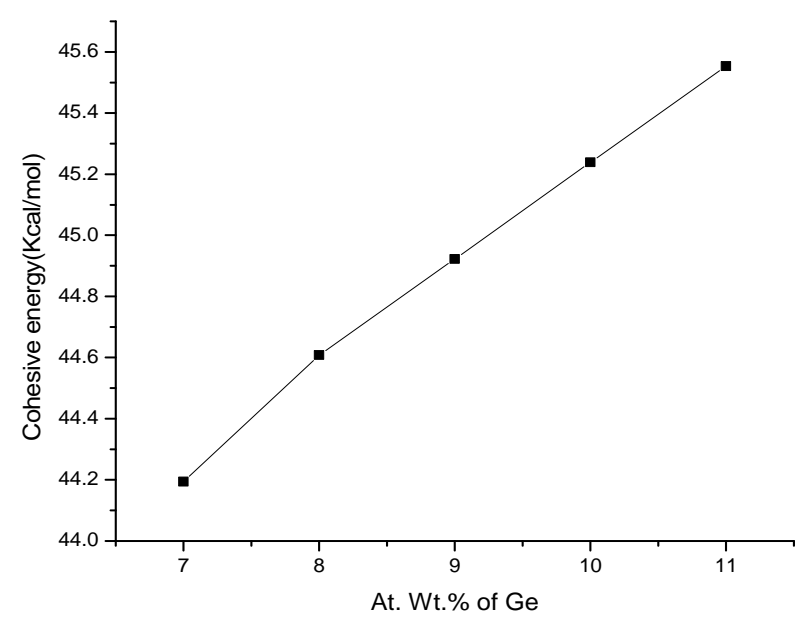

Figure 4. Variation of cohesive energy with Ge content.
The average heat of atomization $H_{s}$ is defined for a quaternary compound. $A_{\alpha} B_{\beta} C_{\gamma} D_{\delta}$, as [24]

$$
\bar{H}_{S}=\frac{\alpha H_{S}^{A}+\beta H_{S}^{B}+\gamma H_{S}^{C}+\delta H_{S}^{D}}{\alpha+\beta+\gamma+\delta}
$$

where $\alpha, \beta, \gamma$ and $\delta$ are the atomic percentages of $A, B, C$ and $D$ respectively. In case of chalcogenide glasses the heat of formation contributes very little towards the average heat of atomization because the electro negativities of the constituent elements are very similar and in most of the cases of chalcogenide glasses the heat of formation is unknown. In the few materials for which heat of formation is known it accounts only $10 \%$ for the heat of atomization and is therefore neglected. The heat of atomization are as, $H_{s}(\mathrm{~Pb})=195 \mathrm{KJ} / \mathrm{mol}, H_{s}(\mathrm{Sn})=302$ $\mathrm{KJ} / \mathrm{mol}, H_{s}(\mathrm{Se})=227 \mathrm{KJ} / \mathrm{mol}, H_{s}(\mathrm{Ge})=377 \mathrm{KJ} / \mathrm{mol}$ [25-27]. The values of heat of atomization for chalcogenide glasses are given in Table 3 .

The variation of the heat of the atomization with increasing the Ge content is shown in Figure 5. It is evident from the Figure 5 that with increasing the concentration of the Ge (or decreasing the concentration of $\mathrm{Pb}$ ) there is an increase in the heat of the atomization, this is due to the fact that heat of atomization of Ge is greater than that of $\mathrm{Pb}$, that is why there is an increase in the heat

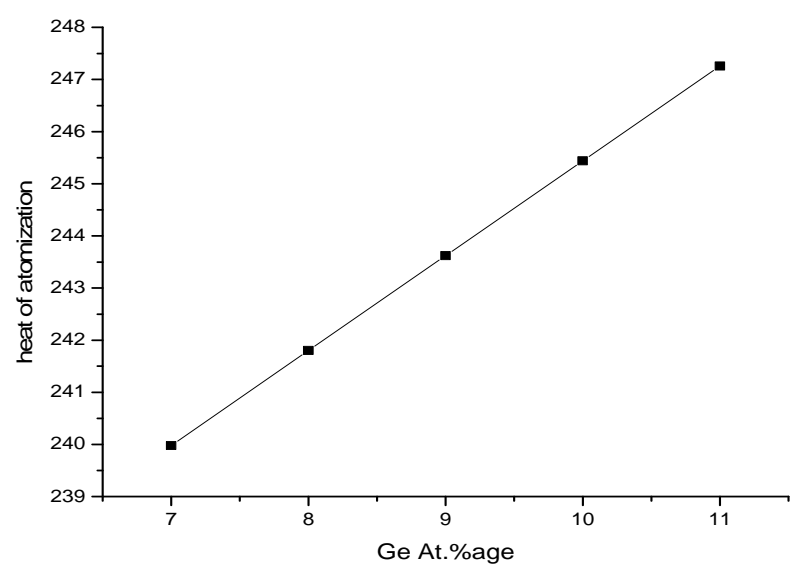

Figure 5. Variation of heat of atomization with Ge content.

Table 2. The Distribution of various possible bonds in $\mathrm{Se}_{74} \mathrm{Sn}_{8} \mathrm{~Pb}_{18-x} \mathrm{Ge}_{x}$ glasses and cohesive energy.

\begin{tabular}{cccccc}
\hline \multirow{2}{*}{$x$} & \multicolumn{4}{c}{ Bonds formed } & \multicolumn{2}{c}{$\begin{array}{c}\text { Cohesive } \\
\text { energy } \\
\text { nycal/mol) }\end{array}$} \\
\cline { 2 - 5 } & Se-Pb & Se-Ge & Sn-Se & Se-Se & Kcal \\
\hline$x=7$ & 0.1486 & 0.1892 & 0.2162 & 0.4460 & 44.19 \\
$x=8$ & 0.1351 & 0.2162 & 0.2162 & 0.4325 & 44.61 \\
$x=9$ & 0.1216 & 0.2432 & 0.2162 & 0.4190 & 44.92 \\
$x=10$ & 0.1081 & 0.2703 & 0.2162 & 0.4054 & 45.24 \\
$x=11$ & 0.0946 & 0.2973 & 0.2162 & 0.3919 & 45.55 \\
\hline
\end{tabular}


of the atomization of the material with increasing Ge content. As a result of which network of the material strengthen and heat of atomization of the material increases.

\subsection{Mean Bond Energy and Glass Transition Temperature}

Considerable attention has been devoted to the prediction of glass transition temperature $\left(T_{g}\right)$ of chalcogenide based glasses. Thorpe and Tichy [28] were first to recognize that in a chemically ordered system, there should be an excellent empirical correlation between the glass transition temperature $\left(T_{g}\right)$ and overall mean bond energy. There is one another model proposed by Lankhorst [29] in order to estimate the glass transition temperature $\left(T_{g}\right)$ especially for phase change materials. In this approach the glass transition temperature $\left(T_{g}\right)$ is estimated using enthalpy of atomization.

The covalent bond approach of Tichy and Ticha $[17,18]$ may be considered as a first approximation in the case of chalcogenide glasses. The glass transition temperature is considered to be proportional to the mean bond energy $\langle E\rangle$, which depends on factors like average coordination number, degree of cross linking, bond energy and the nature of the bonds. The overall mean bond energy for the system $\mathrm{Se}_{\mathrm{a}} \mathrm{Ge}_{b} \mathrm{Sn}_{\mathrm{c}} \mathrm{Pb}_{\mathrm{d}}$ is given by

$$
\langle E\rangle=E_{c l}+E_{r m}
$$

where $E_{c l}$ is the mean bond energy of average cross linking per atom and $E_{r m}$ is the average bond energy per atom of the remaining matrix of bonds using a set of 186 glasses.

$$
E_{c l}=P_{r} D_{h b}
$$

Here $P_{r}$ is the degree of cross linking and $D_{h b}$ is the average heteropolar bond energy, Tichy and Ticha illustrated an impressive correlation of $T_{g}$ with mean bond energy in the form

$$
T_{g}=311[\langle E\rangle-0.9]
$$

Lankhorst [28] found an empirical relation between $T_{g}$ (Kelvin) and enthalpy of atomization $H_{s}(\mathrm{~kJ} / \mathrm{g}$ atom) which is given by

$$
T_{g}=3.44 H_{s}-480
$$

The slope of 3.44 is in reasonable agreement with the value of $311 \mathrm{~K} / \mathrm{eV}$ or $3.23 \mathrm{~K} /(\mathrm{kJ} / \mathrm{g}$ atom) found by Tichy and Ticha who used a slightly different set of bond energies. The compositional variations of glass transition temperature studied by Tichy Ticha and Lankhorst approaches are shown in Figure 6, the embedded inset shows the variation of bond energy with Ge content.

And respective values of $T_{g}$ and $\langle E\rangle$ are tabulated in the Table 3.

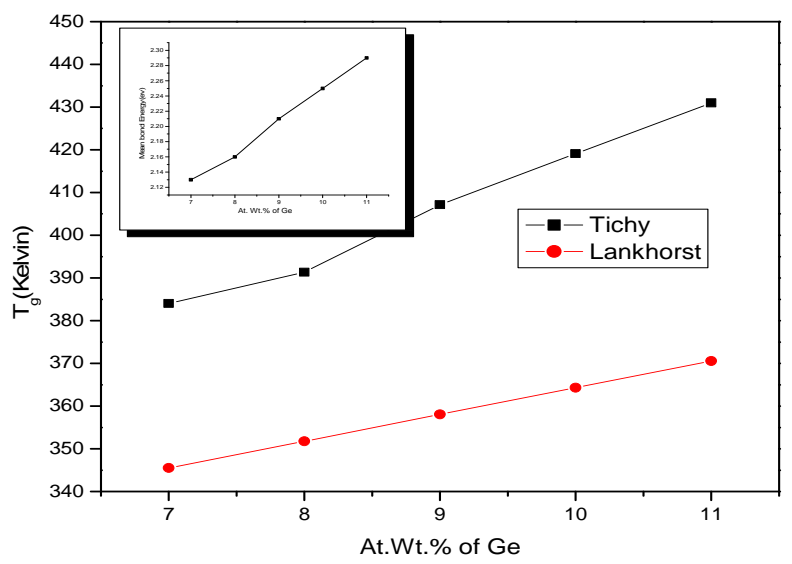

Figure 6. Variation of glass transition temperature $\left(T_{g}\right)$ with Ge content.

Table 3. Values of average heat of atomization $\left(H_{s}\right)$, mean bond energy $<\mathrm{E}>$ and glass transition temperature $T_{g}(\mathrm{~K})$ of chalcogenide system.

\begin{tabular}{ccccc}
\hline \multirow{2}{*}{ Compositon } & $\begin{array}{c}H_{s} \\
(\mathrm{KJ} / \mathrm{Mol})\end{array}$ & $\begin{array}{c}<\mathrm{E}> \\
(\mathrm{eV})\end{array}$ & \multicolumn{2}{c}{$T_{g}(\mathrm{~K})$ by } \\
\cline { 4 - 5 } & & & Tichy & Lankhorst \\
\hline $\mathrm{Se}_{74} \mathrm{Sn}_{8} \mathrm{~Pb}_{11} \mathrm{Ge}_{7}$ & 239.98 & 2.13 & 383.99 & 345.53 \\
$\mathrm{Se}_{74} \mathrm{Sn}_{8} \mathrm{~Pb}_{10} \mathrm{Ge}_{8}$ & 241.80 & 2.16 & 391.33 & 351.79 \\
$\mathrm{Se}_{74} \mathrm{Sn}_{8} \mathrm{~Pb}_{9} \mathrm{Ge}_{9}$ & 243.62 & 2.18 & 407.10 & 358.05 \\
$\mathrm{Se}_{74} \mathrm{Sn}_{8} \mathrm{~Pb}_{8} \mathrm{Ge}_{10}$ & 245.44 & 2.25 & 419.10 & 364.31 \\
$\mathrm{Se}_{74} \mathrm{Sn}_{8} \mathrm{~Pb}_{7} \mathrm{Ge}_{11}$ & 247.26 & 2.29 & 430.95 & 370.57 \\
\hline
\end{tabular}

\section{Conclusion}

The material $\mathrm{Se}_{74} \mathrm{Sn}_{8} \mathrm{~Pb}_{18-x} \mathrm{Ge}_{x}(x=7,8,9,10,11)$ formed is amorphous in natures as confirmed through $\mathrm{XRD}$. The sample at $x=3$ is crystalline in nature that might be due to under constrained network having low coordination number. There are some structural inhomogeneities in the material which might be due to partial phase separation as it is obvious in the XRD diffractograms and SEM micrographs also. Increasing Ge content increases the degree of cross linking and produces the condition for good glass formation. The physical parameters such as heat of atomization, cohesive energy and mean bond energy have monotonic increasing trend as a consequent of increased degree of cross linking in glassy matrix and hence glass transition temperature of the material also increases.

\section{REFERENCES}

[1] S. R. Ovshinsky, "Reversible Electrical Switching Phenomena in Disordered Structures," Physical Review Letters, Vol. 21, No. 20, 1968, pp. 1450-1453. http://dx.doi.org/10.1103/PhysRevLett.21.1450 
[2] S. Ovshinsky, "Amorphous Materials-The Key to New Devices," IEEE Proceedings of Circuits and Systems, Vol. 1, 1998, p. 33.

[3] J. Feinleib, J. de Neufville, S. C. Moss and S. R. Ovshinsky, "Rapid Reversible Light-Induced Crystallization of Amorphous Semiconductors," Applied Physics Letters, Vol. 18, No. 6, 1971, pp. 254-257. http://dx.doi.org/10.1063/1.1653653

[4] A. B. Seddon, "Chalcogenide Glasses: A Review of Their Preparation, Properties and Applications," Journal of Non-Crystalline Solids, Vol. 184, 1995, pp. 44-50. http://dx.doi.org/10.1016/0022-3093(94)00686-5

[5] B. Vaidhyanathan, S. Murugavel, S. Asokan and K. J. Rao, "Origin of Carrier-Type Reversal in Pb-Ge-Se Glasses: A Detailed Thermal, Electrical, and Structural Study," The Journal of Physical Chemistry B, Vol. 101, No. 47, 1997, pp. 9717-9726. http://dx.doi.org/10.1021/jp972129+

[6] S. Murugavel and S. Asokan, "Carrier-Type Reversal in Pb-Modified Chalcogenide Glasses," Physical Review B, Vol. 58, No. 8, 1998, pp. 4449-4453. http://dx.doi.org/10.1103/PhysRevB.58.4449

[7] R. Ganesan, B. Thangaraju, K. S. Sangunni and E. S. R. Gopal, "Carrier Type Reversal in $\mathrm{Pb}_{x} \mathrm{Ge}_{42-x} \mathrm{Se}_{58}$ and $\mathrm{Pb}_{20} \mathrm{Ge}_{y} \mathrm{Se}_{80-y}$ Glasses Exhibited in Thermal Diffusivity Measurements," Journal of Optoelectronics and Advanced Materials, Vol. 3, No. 2, 2001, pp. 467-472.

[8] S. Jayakumar, P. Predeep and C. Harikuttan Unnithan, "Topology of Chemical Ordering in Sb-S-Ge System," Physica Scripta, Vol. 66, No. 2, 2002, pp. 180-182. http://dx.doi.org/10.1238/Physica.Regular.066a00180

[9] N. F. Mott and E. A. Davis, "Electronic Processes in Non-Crystalline Materials," Clarendon Press, Oxford, 1979.

[10] G. G. Naumis, "Contribution of Floppy Modes to the Heat Capacity Jump and Fragility in Chalcogenide Glasses," Physical Review B, Vol. 61, No. 14, 2000, pp. R9205-R9208.

[11] M. F. Thorpe, "Continuous Deformations in Random Networks," Journal of Non-Crystalline Solids, Vol. 57, 1983, pp. 355-370. http://dx.doi.org/10.1016/0022-3093(83)90424-6

[12] V. Modgil and V. S. Rangra, "The Study of the Theoretical Parameters of Ge Sn Substituted Pb Based Quaternary Chalcogenide Glasses at Their Rigidity Percolation Threshold," Journal of Optoelectronic and Advanced Materials, Vol. 13, No. 2, 2011, pp. 158-164.

[13] P. Boolchand, D. G. Georgiev and B. Goodman, "Discovery of the Intermediate Phase in Chalcogenide Glasses," Journal of Optoelectronics and Advanced Materials, Vol. 3, No. 3, 2001, pp. 703-720.

[14] P. K. Gupta and J. C. Mauro, "Composition Dependence of Glass Transition Temperature and Fragility. 1. A Topological Model Incorporating Temperature-Dependent Con- straints," The Journal of Chemical Physics, Vol. 130, No. 9, 2009, Article ID: 094503. http://dx.doi.org/10.1063/1.3077168

[15] A. George, D. Sushamma and P. Predeep, "Effect of Indium Content on the Optical and Other Physical Characterstics of As-Te Glass System," Chalcogenide Letters, Vol. 3, No. 4, 2006, pp. 33-39.

[16] Z. H. Liang, "Chemical Bond Approach to the Chalcogenide Glass Forming Tendency," Journal of Non-Crystalline Solids, Vol. 127, No. 6, 1991, pp. 298-305. http://dx.doi.org/10.1016/0022-3093(91)90482-L

[17] L. Tichy and H. Ticha, "On the Chemical Threshold in Chalcogenide Glasses," Materials Letters, Vol. 21, No. 3-4, 1994, pp. 313-319. http://dx.doi.org/10.1016/0167-577X(94)90196-1

[18] L. Tichy and H. Ticha, "Covalent Bond Approach to the Glass-Transition Temperature of Chalcogenide Glasses," Journal of Non-Crystalline Solids, Vol. 189, No. 1-2, 1995, pp. 141-146.

[19] S. R Elliot, "Physics of Amorphous Solids," Longman Inc., New York, 1984.

[20] L. Pauling, "The Nature of the Chemical Bond," Cornell University Press, New York, 1960.

[21] A. K. Pattanaik and A. Srinivasan, "Electrical and Optical Studies on Pb-Modified Amorphous Ge-Se-Te Films," Semiconductor Science and Technology, Vol. 19, No. 2, 2004, p. 157.

[22] I. Haruvi-Busnach, "Chalcogenide Glasses Ge-Sn-Se, Ge-Se-Te, and Ge-Sn-Se-Te for Infrared Optical Fibers," Journal of Materials Research, Vol. 5, No. 6, 1990, pp. 1215-1223.

[23] S. A. Fayek and S. S. Fouad, "Topological Consideration of Thallium on Glassy Arsenous Selenide," Vacuum, Vol. 52, No. 3, 1998, pp. 359-363. http://dx.doi.org/10.1016/S0042-207X(98)00322-4

[24] A. Dahshan and K. A. Aly, "Characterization of New Quaternary Chalcogenide As-Ge-Se-Sb Thin Films," Philosophical Magazine, Vol. 88, No. 3, 2008, pp. 361-372.

[25] H. Ellis, "Nuffield Advanced Science Book of Data," Longman, London, 1972.

[26] A. M. James and M. P. Lord, "Macmillan's Chemical and Physical Data," Macmillan, London, 1992.

[27] J. D. Cox, D. D. Wagman and V. A. Medvedev, "CODATA Key Values for Thermodynamics," Hemisphere Publishing Corp., New York, 1989.

[28] M. F. Thorpe and L. Tichy, "Properties and Applications of Amorphous Materials," Kluwer Academic Press, Dordrecht, 2001.

[29] M. H. R. Lankhorst, "Modelling Glass Transition Temperatures of Chalcogenide Glasses. Applied to PhaseChange Optical Recording Materials," Journal of NonCrystalline Solids, Vol. 297, No. 2-3, 2002, pp. 210-219. 